\title{
Synthesis and Characterization of [Sa(p-anisal-DA)4(H2O)2]by insitu Method
}

\author{
Pandian Paulraj, Madasamy Kumar, Arumugam Sathamraja, Ayyar Manikandan
}

\begin{abstract}
The insitu synthesis of Schiff base metal complex using N-phenyl-1,4-phenylenediamine (DA), p-anisaldehyde (p-anisal) as starting materials with samarium nitrate hexahydrate $(\mathrm{Sa}(\mathrm{NO3}) 2.6 \mathrm{H} 2 \mathrm{O})$ as a metal precursor in the molar ratio (1:1:1 M) at room temperature. The prepared metal complex is washed with several times with ethanol and boiled water for the removal of un-reacted starting materials completely. The following techniques are used to confirm the prepared Schiff base metal complex by $U V$-visible spectroscopy, Fourier Transforms Infrared spectroscopy, X-ray diffraction pattern and Cyclic Voltammetry.
\end{abstract}

Keywords: Schiff base, Metal complexes, Insitu method, cyclic voltammetry

\section{INTRODUCTION}

The Schiff bases compounds having functional groups in its ligand that contains $\mathrm{C}=\mathrm{N}$ by the condensation reaction which are usually synthesized using active carbonyl groups and aniline substituted amines. Recently, the Schiff bases and complexes were significant in various in pharmaceutical and medicinal field. They display a broad range of biological applications such as antitumor, antifungal, antiviral and antibacterial activity [1-9] and also these types of complexes having higher steric hindrance nature by introducing the bulkier substituent in its existing molecules. The stabilization of metal complexes by its metal oxidation nature and it gives good solubility for the spectrum analysis [10-12]. The DA has much interest in the preparation of Schiff base metal complex because it has lower potential than aniline so which easily involved the reaction by donating the electron and react with p-anisal give the Schiff base ligand at room temperature easily. Likewise in the presence of metal salts, the starting materials react with $\mathrm{Sa}(\mathrm{NO} 3) 2.6 \mathrm{H} 2 \mathrm{O}$ give the Schiff base metal complex via insitu method [13-15]. The insitu method have been several benefits in Schiff base synthesis, which has various In this present investigation, aniline based amines were used for the formation of ligand with easily reacted aldehyde and it's for metal complexes, the

Revised Manuscript Received on December 11, 2019

Pandian Paulraj, Assistant Professor, Department Of Science \& Humanities, Bharath Institute Of Higher Education And Research TamilNadu,India.Email: paulrajp.che@bharathuniv.ac.in

Madasamy Kumar,, Department Of Science \& Humanities, Bharath Institute Of Higher Education And Research TamilNadu,IndiaEmail: kmrorg@gmail.com

Arumugam Sathamraja Department Of Science \& Humanities, Bharath Institute Of Higher Education And Research TamilNadu,IndiaEmail: sathamrajaarumugam@gmail.com

Ayyar Manikandan Department Of Science \& Humanities, Bharath Institute Of Higher Education And Research TamilNadu,IndiaEmail: mkavath15@gmail.com corresponding metal precursor is used with amine and aldehyde and especially the insitu approaches followed for the synthesis of metal complexes [16,17]. This approach has various benefits especially friendly approach to our environmental, cost effect with atom economy, less hazardous nature. Generally, the formation of schiff base ligand by the reaction of aromatic amine with carbonyl compound (aldehyde) via hemiaminal followed by the imines formation through nucleophilic addition reaction [18-27].

\section{EXPERIMENTAL METHOD AND TECHNIQUES}

\section{A. Chemicals}

The analar grade chemicals and solvents were used as received without purification for the synthesis. The high purity salts of DA, p-Anisaldehyde, Methanol, Ethanol, samarium nitrate were purchased from Fluka and Lancaster Chemical company.

\section{B. Instrumentation}

The information of the stability and structures of the materials can be discovering by UV-vis. spectrophotometer. The spectra was recorded with C-driven model UV-1800 (Shimadzu), Japan spectrophotometer (resolution $0.1 \mathrm{~nm}$ ). FT-IR is one of the very important tool to find what are the functional groups are present in the molecules and modification on the metal surfaces (coating), which is used to prevent the growth of the nanoparticles by aggregation as well as the surface phenomenon of the inorganic metal nanoparticles. The FT-IR spectrophotometer for the analysis of the samples in Perkin-Elmer, USA Y-40 model within the range of $400-4000 \mathrm{~cm}^{-1}$. All spectra were correct with reference background spectrum of $\mathrm{KBr}$. XRD pattern taken with a Philips instrument (JSO Debye Flex 2002 Seifert) at a $10^{\circ} / \mathrm{min}$ scanning speed from $10^{\circ}$ to $80^{\circ}$. And its electrochemical measurements are carrying out using a CHI-660A (CHI Instruments Co. USA) electrochemical workstation. All the solutions were prepared for the electrochemical investigation used to purged the $\mathrm{N}_{2}$ gas for 10 minutes before the stating the analysis

\section{RESULTS \& DISCUSSION}

\section{A. Synthesis of [Sa(p-anisal-DA)4(H2O)2] complex}

The 1:1 M ratio of DA and $p$-anisal were dissolved in ethanol separately. 
The methanolic solution of $p$-anisal was added drop wise in the stirred solution of DA till 19-15 mins and then the reaction was allowed $5 \mathrm{hr}$. A brown colored precipitate was formed after 30 minutes, which is confirms the formation of metal complexes via insitu complexation method. After the completion of reaction, the reaction mixture is brown in colour which are separated by filtration and washed many times till the removal of un-reacted starting materials and dried in vacuum
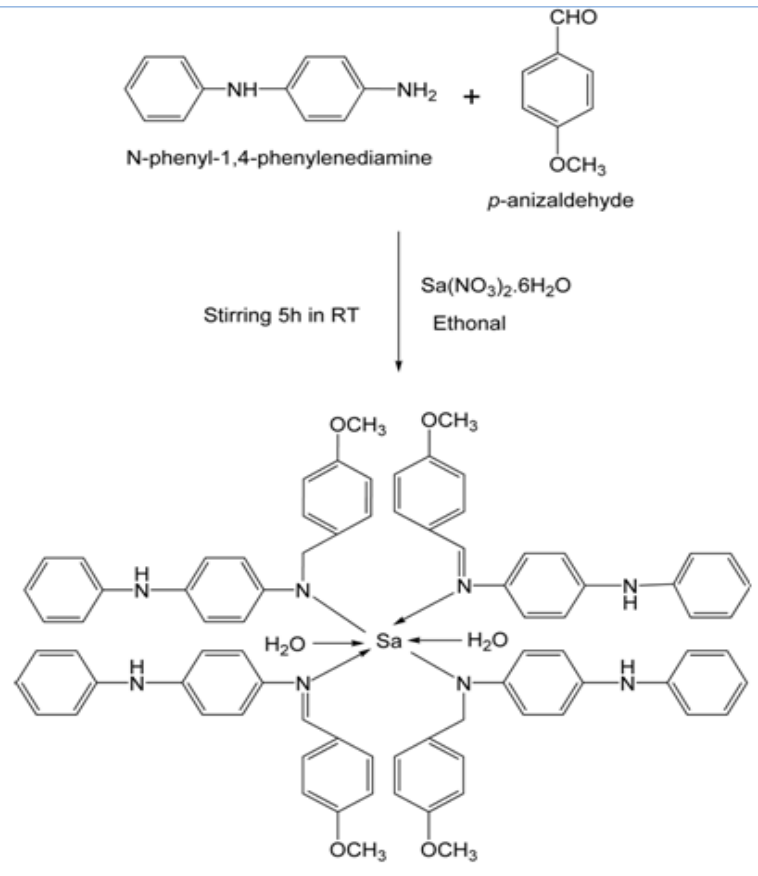

\section{B. UV-visible spectral analysis}

Figure 1 shows the UV-visible spectrum of $\left[\mathrm{Sa}(p \text {-anisal-DA })_{4}\left(\mathrm{H}_{2} \mathrm{O}\right)_{2}\right]$. When UV-visible spectrum was recorded in $\mathrm{CH}_{3} \mathrm{CN}$ medium, three distinct bands were observed at 240-270 nm, 290-320 nm, and above $400 \mathrm{~nm}$. The bands at below $270 \mathrm{~nm}$ is due to the $\pi-\pi^{*}$ transition of the benzenoid ring and the band at $300 \mathrm{~nm}$ is attributed the charge transfer of ligand to metal (LMCT) and also the observation of the band at $311 \mathrm{~nm}$ is the feature mark of the transition of ligand to ligand charge transfer ( $\left.p-p^{\prime}\right)$. The $\pi-\pi^{*}$ transition is appeared above $400 \mathrm{~nm}$. In this case, the shoulder peak was obtained at $\sim 450 \mathrm{~nm}$ can be assigned to the low wavelength polaron- $\pi *$ characteristic band and the bulkier methoxy group attached in the benzene ring which is due to of the prepared compounds. These spectrum were confirmed that the formation of $\left[\mathrm{Sa}(p \text {-anisal-DA })_{4}\left(\mathrm{H}_{2} \mathrm{O}\right)_{2}\right]$ successfully by in-situ method.

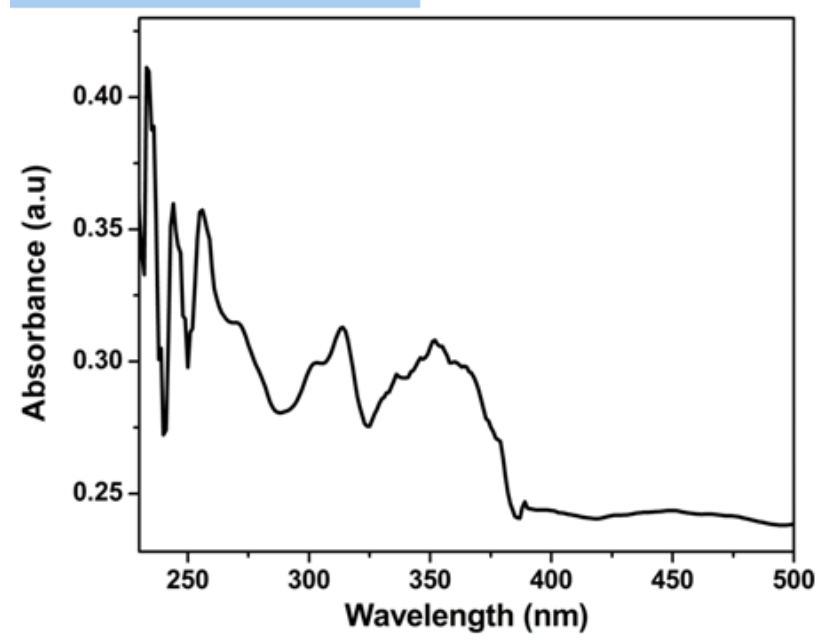

Fig.2. UV-visible spectrum of $\left[\mathrm{Sa}(p \text {-anisal-DA })_{4}\left(\mathrm{H}_{2} \mathrm{O}\right)_{2}\right]$.

\section{Fourier Transforms Infra-red Spectroscopy}

Figure 2 shows the FT-IR spectrum of [Sa $\left.(p \text {-anisal-DA })_{4}\left(\mathrm{H}_{2} \mathrm{O}\right)_{2}\right]$. The ligand has average intense peaks at 1249, 1610, and $1695 \mathrm{~cm}-1$ are for $v(C-O), v(C=N)$ and $v(\mathrm{C}=\mathrm{O})$, respectively. The response in the region of $540-590 \mathrm{~cm}-1$ and $470-500 \mathrm{~cm}-1$ are assigned to $v(\mathrm{M}-\mathrm{N})$ and $v(\mathrm{M}-\mathrm{O})$ stretching vibrations were conform the metal are strongly bound with ligand successively. The wide response between in 3149-3300 cm-1 observed the complex having hydrated by its broad response. The bands at 2800-3000 cm-1 due to the stretching of $v(\mathrm{C}-\mathrm{H})$ and the band at $\sim 1598 \mathrm{~cm}-1$ due to the stretching vibration of $v(\mathrm{C}=\mathrm{C})$ and the responses of aldehyde $v(\mathrm{C}-\mathrm{H})$ obtained at $1309 \mathrm{~cm}-1$. Some of the bands of metal complexes are observed at slightly lower region compared with pure ligand, which confirms the metals were coordinated with Schiff base ligand. Some of the bands of metal complexe are observed at slightly lower region compared with pure ligand, which is confirms the metal coordinated with Schiff base ligand.

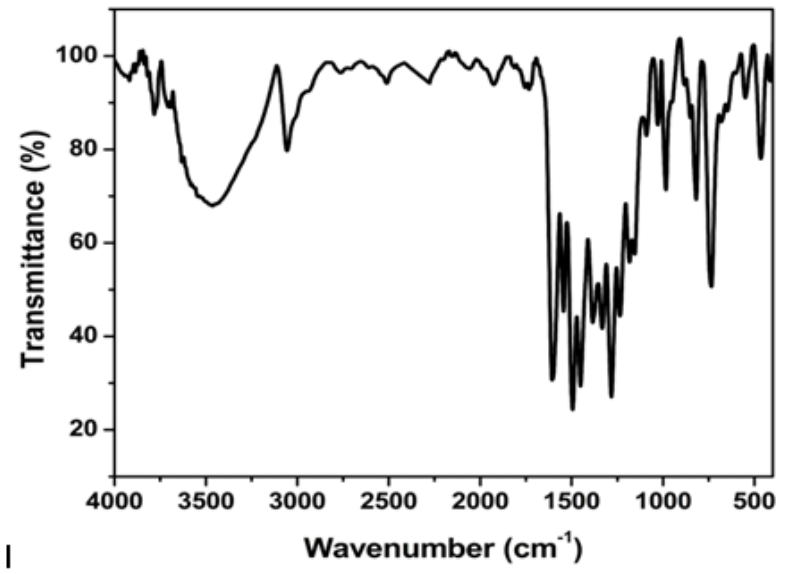

Fig.3. FT-IR spectrum of [Sa $\left.(p \text {-anisal-DA })_{4}\left(\mathrm{H}_{2} \mathrm{O}\right)_{2}\right]$. . X-ray Diffraction studies

Figure 3 shows the XRD spectrum of $\left[\mathrm{Sa}(p \text {-anisal-DA })_{4}\left(\mathrm{H}_{2} \mathrm{O}\right)_{2}\right]$. The prepared metal complexes having well crystalline sharp peak in its pattern due to its well crystalline nature and also it has considerable change in its pattern $[22,23]$. 
The grain nature and its size obtained using Scherre's formula using it's the value of full width half maximum peak value. By these spectra we can easily find out the nature of crystallinity of the metal complexes by the observation of the broad band's at $2 \theta=15-30$.

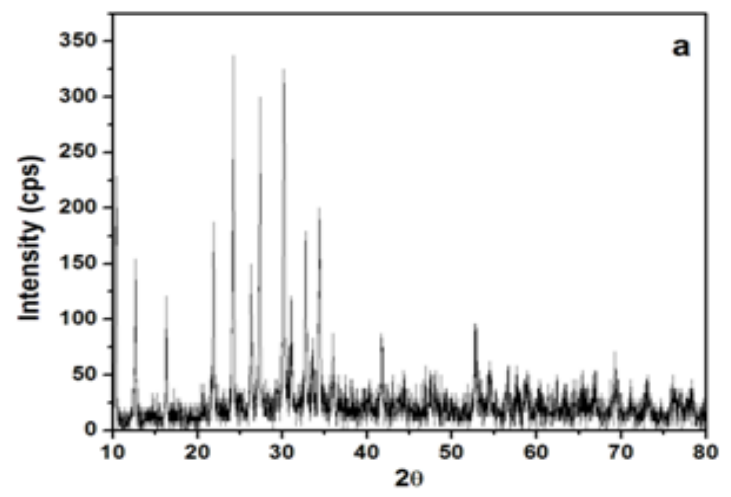

Fig.4. XRD spectrum of [Sa( $p$-anisal-DA $\left.)_{4}\left(\mathrm{H}_{2} \mathrm{O}\right)_{2}\right]$. The modified electrode was prepared after polishing with alumina powder with washing with water, sample amount near $2 \mathrm{mg}$ of complex placed on micro slide and add few drop of methanol for making it wet and rub over the surface of GCE for adhering the metal complex on the GCE surface and dried well. All the solution were prepared with purity and purge with N2 air to remove the presence of oxygenated air making it fit for analysis before 10 minutes of measurements. Electrochemical responses of anizaldehyde-toluidine based Schiff base metal complexes

Figure 4 shows the electrochemical response of [Sa $\left.(p \text {-anisal-DA })_{4}\left(\mathrm{H}_{2} \mathrm{O}\right)_{2}\right]$ in $0.1 \mathrm{M} \mathrm{PBS}(\mathrm{pH} 6)$ at scan rate $50 \mathrm{mV}$. The metallic Schiff base complex has strong and irreversible peak at $+0.72 \mathrm{~V}$ due to its irreversible anodic responses of the one-electron oxidation for the bulkier group. Three coupled peaks are reversible but small in size responses observed at $(-0.19 \mathrm{~V},-0.51 \mathrm{~V}),(+0.007 \mathrm{~V},-0.35 \mathrm{~V})$ and $(+0.22 \mathrm{~V},-0.13 \mathrm{~V})$, which is attributed for the transformation of the metal (M) like $\mathrm{M}(\mathrm{III}) / \mathrm{M}(\mathrm{II})$, $\mathrm{M}(\mathrm{II}) / \mathrm{M}(\mathrm{I})$ and $\mathrm{M}(\mathrm{I}) / \mathrm{M}(0)$ in the oxidation as well as reduction so it confirms the metal complex having three oxidation state and its more redox properties reversible nature. The one broad strong irreversible peak observed at $+0.72 \mathrm{~V}$ for the electron transfer in the ligand to metal.

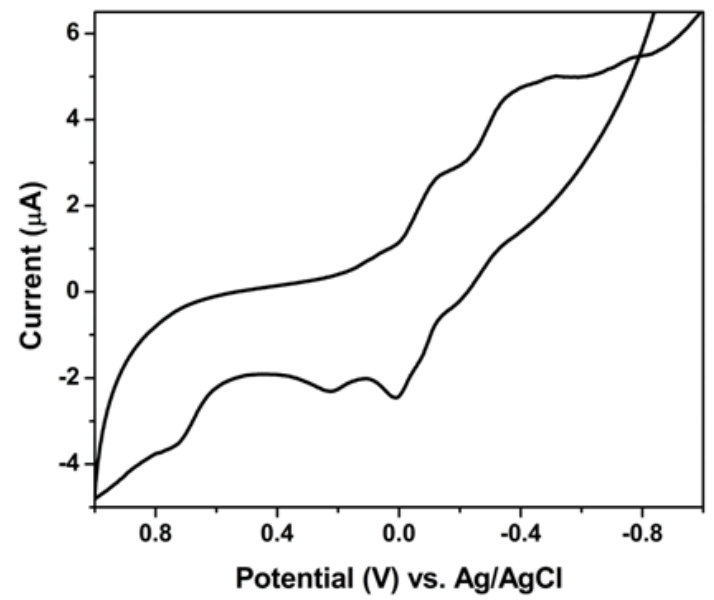

Fig.4. CV spectrum of [Sa(p-anisal-DA $\left.)_{4}\left(\mathrm{H}_{2} \mathrm{O}\right)_{2}\right]$ in $0.1 \mathrm{M}$ PBS (pH 6) at scan rate $50 \mathrm{mV}$

\section{REFERENCES}

1. I. Dilovic, M. Rubcic, V. Vrdoljak, S.K. Pavelic, M. Kralj, I. Piantanida M. Cindric, Bioorg. Med. Chem. 16 (2008) 5189.

2. A. Jarrahpour, M. Motamedifar, K. Pakshir, N. Hadi, M. Zarei, Molecules 9 (2004) 815.

3. P. Bhavani, A. Manikandan, P. Paulraj, A. Dinesh, M. Durka, S. Aru Antony, J. Nanosci. Nanotechnol. 18 (2018) 4072-4081

4. P.H. Wang, J.G. Keck, E.J. Lien, M.M.C. Lai, J. Med. Chem. 33 (1990) 608.

5. P. Paulraj, N. Janaki, S. Sandhya, K. Pandian, Colloids and Surfaces A Physicochem. Eng. Aspects 377 (2011) 28-34.

6. A. Das, M.D. Trousdale, S. Ren, E.J. Lien, Antiviral Res. 44 (1999) 201.

7. Kumar M, Sribalan R, and Padmini* V, Chemistry Select, 2016, 1, 1 6.

8. P. Paulraj, A. Manikandan, E. Manikandan, K. Pandian, M. K Moodley, K. Roro, K. Murugan, J. Nanosci. Nanotechnol. 18 (2018) 3991-3999.

9. R. Mladenova, M. Ignatova, N. Manolova, T. Petrova, I. Rashkov, Eur. Polym. J. 38 (2002) 989.

10. O.M. Walsh, M.J. Meegan, R.M. Prendergast, T.A. Nakib, Eur. J. Med.Chem. 31 (1996) 989.

11. Kumar M, Padmini V*, Ponnuvel K, J.Saudi Chem. Soc, (2014): http:// dx.doi.org/ 10.1016/ j.jscs.2014.03.006

12. K. Kaviyarasu, E. Manikandan, P. Paulraj, S. B. Mohamed, J. Kennedy, J. Alloys Compd.593 (2014) 67-70.

13. G. Ceyhana, S. Urus, I. Demirtas, M. Elmastas, M. Tumera, Spectrochim. Acta. A. 81 (2011) 184.

14. F. Ragaini, Dalton Trans. 2009, 2009, 6251-6266. 71

15. Y.c. Liu, Z.y. Yang, J. Organomet. Chem. 694 (2009) 3091.

16. Kumar M, Padmini V*, Bhuvanesh N, Res. Chem. Intermediates., 2017, 8, 4517-4530.

17. B.K. Santra, P.A.N. Reddy, G. Neelakanta, S. Mahadevan, M. Nethaji, A.R. Chakravarty, J. Inorg. Biochem. 89 (2002) 191.

18. D. de Bellefeuille, M.S. Askari, B. Lassalle-Kaiser, Y. Journaux, A. Aukauloo, M. Orio, F. Thomas, X. Ottenwaelder, Inorg. Chem. 51 (2012) 12796.

19. V. S. V. Satyanarayana, P. Sreevani, A. Sivakumar, V. Vijayakumar, Arkivoc 2008, 221-233 (2008)

20. V. Patel, P. Trivedi, , H. Gohel, D. Khetani, Int. J. Adv. Pharmacy, Biol. Chem. 3, 999-1003 (2014)

21. R. Marx Nirmal, P. Paulraj, K. Pandian, K. Sivakumar, AIP Conf. Proc. 1391(2011) 597-599

22. Ponnuvel K, Kumar M, Padmini V *, Sensors and Actuators B: chemical, 2016, 227, 242-247.

23. M. A. Ashraf, K. Mahmood, A. Wajid, M. J. Maah, I. Yusoff, Int. Conf Chem. adn Chem. Process 10, 1-7 (2011).

24. D.J. Díaz, A. K. Darko, L. McElwee-White, Eur. J. Org. Chem. 2007, 4453-4465. 70.

25. B. Gabriele, R. Mancuso, G. Salerno, Eur. J. Org. Chem. 2012, 6825-6839.

26. E. Prabakaran, S. Parani, M. Alexander, P. Paulraj, K. Pandian, J. Nanosci. Lett. 3 (2013) 1-9.

27. N. R. Bader, RASAYAN J. Chem. 3, 660-670 (2010).

\section{CONCLUSION}

The developments of the field of synthesizing new metal complexes are grown rapidly. The Schiff base transition metal complexes have numerous applications in various fields. In this present work, we followed the in-situ root to synthesize the Schiff base Samarium complexes using in-situ root of complex formation in room temperature. For the ligand preparation $\mathrm{p}$-anizaldehyde and $\mathrm{p}$-toluidine was used as monomer and nitrate salt of Samarium was used as metal precursor.

The ligand and its Pd complex are prepared under inert atmosphere, which are Samarium Schiff base metal complex [Sa(p-anisal-DA)4(H2O)2]. To confirm the formation of ligand and its complexes by some spectruml studies which 
are UV-Vis, FT-IR, XRD and CV, which are confirms the synthesis of [Sa(p-anisal-DA)4(H2O)2] were synthesized successfully by using in-situ method.

\section{AUTHORS PROFILE}

Pandian Paulraj, Associate Professor, Department Of Science \& Humanities, Bharath Institute Of Higher Education And Research TamilNadu,India

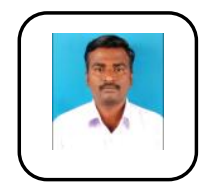

Madasamy Kumar, Associate Professor Departmen Of Science \& Humanities, Bharath Institute Of Higher Education And Research TamilNadu,India

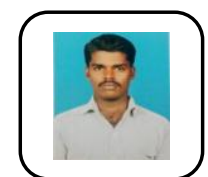

Arumugam Sathamraja Lab Instructor Departmen Of Science \& Humanities, Bharath Institute Of Higher Education And Research TamilNadu,India

Ayyar Manikandan Associate Professor Department Of Science \& Humanities, Bharath Institute Of Higher Education And Research TamilNadu,India 